\title{
Misdirected care in a misdirected world
}

\author{
Kamran Abbasi executive editor
}

The BMJ

Hurricanes and floods tell a story of planetary pain and distress. Many of us love our planet but don't fully understand it. Our solutions are misdirected, ignoring what matters to the planet. Our interests come first. The same applies to patients. Many of us love our patients but struggle to understand their motivations. Our solutions are misdirected.

Victoria Wright has a facial disfigurement. Born with cherubism, she looked like any other girl until the age of 4 . Then, her jaw grew bigger, her eyes began to protrude, and the bridge of her nose flattened. Now in her 30s, Wright continues to refuse surgery to reduce her lower jaw. Her disfigurement, she says, "is entwined with my sense of identity." Yet, when she sees doctors for unrelated problems they sometimes focus on her jaw and tell her that they know excellent surgeons. The question she'd prefer to be asked, and isn't, is whether there is anything else doctors could do to support her (doi:10.1136/bmj.j4068).

A focus on treating a clinical problem can obscure what matters to a patient. A chronic disease might feel like a life

sentence-type 2 diabetes is a perfect example-but should we consider people differently once it is in remission? Louise McCombie and colleagues suggest that celebrating success of remission is a powerful motivator for people with type 2 diabetes to maintain weight loss (doi:10.1136/bmj.j4030). Changing diagnostic coding to reflect remission is likely to deliver better clinical outcomes and reduced healthcare costs.

What happens, though, when diagnosis is controlled by patients? Google is working with the US National Alliance on Mental Illness to offer an online screening test (PHQ-9) to anybody searching for terms such as "Am I depressed?" The alliance's Ken Duckworth believes that using a standard diagnostic test helps patients seek support and that overtreatment is unlikely, as therapy will still be prescribed by a clinician (doi:10.1136/ bmj.j4144). Simon Gilbody, in reply, worries that the case for screening is dubious and that Google's scheme will largely pick up transient psychological distress.

In an accompanying commentary that epitomises this week's subtle theme of misdirected care, the patient David Gilbert observes that Google's offer of a diagnostic test is merely a transfer of paternalistic care to the digital world (doi:10.1136/ bmj.j4207). The power of online tools, he argues, will be realised only once service users are equal partners in policy, planning, and delivery of health services. 